\title{
Nitric Oxide Boosts Bemisia tabaci Performance Through the Suppression of Jasmonic Acid Signaling Pathway in Tobacco Plants
}

\author{
Yanan Xu ${ }^{1+}$, Cheng $\mathrm{Qu}^{1+}$, Xia Sun ${ }^{1}$, Zhifei Jia ${ }^{1}$, Ming Xue ${ }^{1}$, Haipeng Zhao ${ }^{1 *}$ and \\ Xuguo Zhou ${ }^{2 *}$
}

${ }^{1}$ Shandong Provincial Key Laboratory for Biology of Vegetable Diseases and Insect Pests, College of Plant Protection, Shandong Agricultural University, Tai'an, China, ${ }^{2}$ Department of Entomology, College of Agriculture, Food and Environment, University of Kentucky, Lexington, KY, United States

\section{OPEN ACCESS}

Edited by:

Youjun Zhang,

Institute of Vegetables and Flowers

(CAAS), China

Reviewed by:

Yong Liu,

Hunan Academy of Agricultural

Sciences (CAAS), China

Chen Luo,

Beijing Agriculture and Forestry

Academy of Sciences, China

Evan Preisser,

The University of Rhode Island,

United States

*Correspondence:

Haipeng Zhao

haipeng@sdau.edu.cn

Xuguo Zhou

xuguozhou@uky.edu

${ }^{\dagger}$ These authors have contributed equally to this work

Specialty section: This article was submitted to

Invertebrate Physiology,

a section of the journal

Frontiers in Physiology

Received: 14 May 2020

Accepted: 24 June 2020

Published: 22 July 2020

Citation:

Xu Y, Qu C, Sun X, Jia Z, Xue M, Zhao $H$ and Zhou $X$ (2020) Nitric

Oxide Boosts Bemisia tabaci

Performance Through

the Suppression of Jasmonic Acid

Signaling Pathway in Tobacco Plants.

Front. Physiol. 11:847.

doi: 10.3389/fphys.2020.00847
The intimate relationships between plants and insects start with herbivory, which can be traced back to approximately 420 million year ago. Like many other relationships, a plant-insect interaction can be mutualistic, commensalistic, or antagonistic. Within antagonistic relationships, plants deploy inducible defense to insect phytophagy. Insects, however, can evade/suppress effectual plant defenses by manipulating plant defense signaling. Previously, we showed that the sweet potato whitefly, Bemisia tabaci, a global invasive insect pest, can suppress jasmonic acid (JA)-dependent defenses, thereby enhancing their performance on host plants. Given that nitric oxide (NO), a multifunctional signaling molecule, interacts closely with JA signaling pathway, we hypothesized that NO is involved in the suppression of JA defensive responses. Equipped with an integrated approach, we comprehensively examined this overarching hypothesis. We showed that: (1) tobacco plants responded to $B$. tabaci infestation by accumulating high levels of $\mathrm{NO}$, (2) the exogenous application of sodium nitroprusside, a NO donor, in tobacco plants attracted $B$. tabaci adults and accelerated nymphal development, whereas plants treated with 2-(4-carboxyphenyl)-4,4,5,5tetramethylimidazoline-1-oxyl-3-oxide (cPTIO), a NO scavenger, repelled B. tabaci adults and prolonged nymphal development, and, more importantly, (3) silencing of NOassociated protein 1, a gene associated with $\mathrm{NO}$ accumulation, and CPTIO application disrupted the $B$. tabaci-mediated suppression of $\mathrm{JA}$ in plants. Collectively, these results suggest that: (1) NO signaling is activated by $B$. tabaci infestation, (2) NO is involved in the suppression of JA-dependent plant defense, and, consequently, (3) NO improves $B$. tabaci performance on host plants. Our study reflects the remarkable arm race that co-evolved for millions of years between plants and insects and offers a potential novel target (nitric oxide) for the long-term sustainable management of this global invasive pest.

Keywords: Bemisia tabaci, nitric oxide, jasmonic acid, plant defense, tobacco

Abbreviations: cPTIO, 2-4-carboxyphenyl-4,4,5,5-tetramethylimidazoline-1-oxyl-3-oxide; DAF-FM-DA, 4- amino-5methylamino-2', $7^{\prime}$-difluorofluorescein diacetate; DTT, dithiothreitol; ETH, ethylene; JA, jasmonic acid; NO, nitric oxide; NOS, nitric oxide synthase; NR, nitrate reductase; SA, salicylic acid; SNAP, $S$-nitroso- $N$-acetyl-penicillamine; SNP, sodium nitroprusside; TbCSV, tobacco curly shoot virus. 


\section{INTRODUCTION}

As a result of the long-term co-evolution with insects, plants have evolved innate defensive systems to protect themselves from herbivore attacks (Feeny, 1976; Stam et al., 2014). The induced plant resistance is orchestrated by signaling networks that are directed by the phytohormones JA, SA, ETH, and NO (Scheler et al., 2013; Locato et al., 2016). The JA pathway is predominantly induced in response to wounding and tissue damage by herbivore feeding, resulting in the production of defense proteins, phenolic acids, alkaloids, or terpenoids to fend off these pests (Pieterse et al., 2012). Plants can tailor their defense to a specific attacker through accurately eliciting these signaling pathways (Reymond and Farmer, 1998). Herbivores can exploit effectors or elicitors to manipulate plant defensive responses for their own benefit by altering phytohormone biosynthesis or signaling pathways (Zarate et al., 2007; Luan et al., 2013). For instance, in the beet armyworm, Spodoptera exigua, feeding can directly suppress JA effectual defense and thereby enhance their feeding performance (Weech et al., 2008). Similarly, infestation by the cotton mealybug, Phenacoccus solenopsis, suppresses defensive responses in tomato plants through manipulating the signaling crosstalk between JA and SA (Zhang P. J. et al., 2015).

The sweet potato whitefly, Bemisia tabaci, Middle EastAsia Minor 1 (MEAM1), a global invasive agricultural pest, causes extensive crop damage through phloem feeding and transmitting plant viruses (Liu et al., 2007; Xue et al., 2010). To date, research on $B$. tabaci has focused primarily on inter- and intra-species competition, pesticide resistance, and reproductive interference (Mayer et al., 2002; McKenzie et al., 2002; Liang et al., 2007; Luan et al., 2012). Recently, the manipulation of inducible plant defense has received increased attention for its role in B. tabaci outbreaks (Tan et al., 2017; Wang et al., 2017). The competition among herbivores on the same host may rely heavily on the induced defense reactions (Kaplan and Denno, 2007). For instance, B. tabaci feeding can induce a specific defensive response that renders the host plant less suited for other herbivorous competitors, as observed in cabbage caterpillar, Pieris rapae, greenhouse whitefly, Trialeurodes vaporariorum, green peach aphid, Myzus persicae, vegetable leaf-miner, Liriomyza trifolii, and cotton bollworm, Helicoverpa armigera (Inbar et al., 1999; Zhang S. Z. et al., 2013, Zhang et al., 2014, Zhang X. et al., 2015; Zhao et al., 2019). B. tabaci infestation can suppress the effectual defensive response to facilitate its performance in host plants through manipulating the defense signaling crosstalk (Kempema et al., 2007). Previous studies on tomato and Arabidopsis thaliana have demonstrated that the JA signaling pathway is crucial in mediating induced plant defense against B. tabaci (Zarate et al., 2007; Zhang et al., 2013b, 2018; Shi et al., 2017). Nevertheless, B. tabaci feeding can suppress the induction of JA-regulated genes and defense metabolites in tobacco, A. thaliana, and lima beans (Kempema et al., 2007; Zhang et al., 2009; Luan et al., 2013).

Nitric oxide, a gaseous free radical, is a regulatory molecule that plays a key role in signaling plant growth and development processes, including root development, flowering, and seed dormancy (Mur et al., 2013; Scheler et al., 2013; Simontacchi et al., 2015). Although the importance of NO in plant biology has been well established, the main source of NO production is still unclear. Generally, plant NO production is mainly accomplished by enzymatic mechanisms, whereas the typical NOS protein, unlike the fully recognized NOS in mammals, has not been isolated in land plants (Jeandroz et al., 2016). However, several other pathways have been implicated in modulating plant NO levels. For instance, NR-mediated nitrate reduction contributes to NO formation (Fröhlich and Durner, 2011; Gupta et al., 2011), and a circularly permuted GTPase (cGTPase), NO-associated 1 (NOA1), has also been frequently linked to NO accumulation in plants (Asai and Yoshioka, 2009; Wünsche et al., 2011a).

The NO signaling pathway orchestrates defensive responses to a wide array of stresses, including drought, heavy metals, temperature extremes, salinity, and pathogens (Baudouin, 2011; Corpas et al., 2011; Kwan et al., 2015). Recently, NO has proved to be a multifunctional signaling molecule in plant defense against herbivore pests (Moloi et al., 2015). The involvement of NO in defense against tobacco hawkmoths, Manduca sexta, has been proven in tobacco plants (Wünsche et al., 2011a). In pea, NO is involved in its defense against the pea aphid, Acyrthosiphon pisum (Woźniak et al., 2017). Specifically, NO can affect SA/JA/ET-dependent plant defensive responses via $S$-nitrosylation of cysteine residues of the main transcription factors involved in these signaling cascades (Sun et al., 2012; Simontacchi et al., 2015; Zhou et al., 2015). For instance, NO may alter the transcription level of JA-dependent genes through changing the form of NPR1 and negatively impacting $A O C$, a key factor in JA biosynthesis, in a post-translational modification manner (Romero-Puertas et al., 2008; Caarls et al., 2015). However, the role of $\mathrm{NO}$ signaling in $\mathrm{B}$. tabaci-mediated plant defensive response is still unclear.

Previous research has demonstrated that B. tabaci MEAM1 infestation can suppress the effectual JA defense and thus enhance whitefly performance. Because a close relationship exists between NO production and JA signaling (Huang et al., 2004; $\mathrm{Xu}$ et al., 2005), we hypothesize that NO is involved in the manipulation of $B$. tabaci-induced JA defensive responses. To examine this overarching hypothesis, we integrated fluorescent staining, enzyme-linked immunosorbent, virus-induced gene silencing, spectrophotometry, and quantitative real-time PCR analysis to the following questions: (1) the impact of $B$. tabaci feeding on NO signaling in tobacco plants, (2) the effect of NO on $B$. tabaci performance, and (3) the causal relationship between NO production and JA-mediated defensive pathway.

\section{MATERIALS AND METHODS}

\section{Effect of B. tabaci Infestation on NO Biosynthesis \\ Plants and Insects}

Seeds of tobacco, Nicotiana tabacum L. variety Xanthi-nc, were sown in seedling-raising trays $(50 \mathrm{~cm} \times 25 \mathrm{~cm})$ and maintained under standard greenhouse conditions: $23 \pm 2{ }^{\circ} \mathrm{C}, 75 \pm 5 \%$ relative humidity $(\mathrm{RH})$. When the plants were at the two- to three-leaf stage, they were transplanted into plastic pots $(10 \mathrm{~cm}$ 
depth, $12 \mathrm{~cm}$ diameter) and placed in screened cages (insectproof, $50 \mathrm{~cm} \times 50 \mathrm{~cm} \times 50 \mathrm{~cm} ; 50$ meshes). The plants were regularly fertilized and watered before use at the five-leaf stage.

A colony of B. tabaci, Middle East-Asia Minor 1 (MEAM1), was maintained on tobacco plants in the greenhouse for over 50 generations, and its identity was confirmed by a mitochondrial DNA COI marker (AY582867). All bioassays were conducted in an artificial climate chamber (RTOP-D model, Top Instrument Corporation, Zhejiang, China) under the following conditions: $L / D=12: 12 \mathrm{~h}, 23 \pm 2^{\circ} \mathrm{C}, 75 \pm 5 \% \mathrm{RH}$.

\section{Bemisia tabaci Infestation Experiments}

Tobacco plants were infested with $B$. tabaci following Xue et al. (2010). Specifically, the five-leaf stage tobacco plants were placed in a screen cage $(50 \mathrm{~cm} \times 50 \mathrm{~cm} \times 50 \mathrm{~cm})$, and newly emerged whitefly adults $(500 \pm 10$, female/male $\approx 1: 1)$ were released into each cage. The whitefly adults were allowed to feed and oviposit on the plant for $24 \mathrm{~h}$ and were removed using an aspirator. Egg hatching and nymph development were then allowed. Plants caged without whitefly were the control plants. Leaves from infested and control plants were sampled at days 5, 10, and 15, respectively, i.e., corresponding to the 1 st, 2 nd, and 3 rd nymph instar after the removal of adults. The fourth leaf (nine to 10 nymphs $/ \mathrm{cm}^{2}$ ) was sampled for biochemical determination. Each treatment had six biological replicates per sampling date.

\section{Nitric Oxide Analysis}

Intracellular NO levels were detected using a method reported by Drzewiecka et al. (2014), with minor modifications. The fluorescent dye 4-amino-5-methylamino- $2^{\prime}, 7^{\prime}$ difluorofluorescein diacetate (DAF-FM-DA, Beyotime, China) was used for NO level measurements. The tobacco leaves were immersed in $10 \mu \mathrm{M}$ DAF-FM-DA solution for $30 \mathrm{~min}$, washed three times with $20 \mathrm{mM}$ HEPES-NaOH buffer, and mounted on a Zeiss LSM 880 inverted confocal laser scanning microscope system (Carl Zeiss, Oberkochen, Germany; emission wavelength, 515-530 nm) to estimate the fluorescence. NO content was further detected using the NO assay kit (Beyotime, China), following the user instructions. The concentration of NO was expressed in $\mu \mathrm{mol} / \mathrm{g}$ protein. Each treatment had six biological replicates per sampling date.

\section{Nitrate Reductase Activity Assay}

Tobacco leaves $(1 \mathrm{~g})$ were ground with $10 \mathrm{ml}$ of extraction buffer containing $100 \mathrm{mM}$ Hepes- $\mathrm{KOH}$ ( $\mathrm{pH}$ 7.5), $5 \mathrm{mM}$ dithiothreitol, $1 \mathrm{mM}$ EDTA, 10\% (v/v) glycerol, 0.1\% Triton X-100, $1 \mu \mathrm{M}$ leupeptin, $20 \mu \mathrm{M}$ FAD, $0.5 \mathrm{mM}$ phenylmethylsulfonyl fluoride, $1 \%$ polyvinylpyrrolidone, and $5 \mu \mathrm{M} \mathrm{Na} \mathrm{MoO}_{4}$. The tissue homogenate was centrifuged at $12,000 \mathrm{~g}$ for $20 \mathrm{~min}$, the supernatant of which was retrieved for measurement of NR activities. The NR activity was detected according to the method of Scheible et al. (1997) with modifications. To detect NR activity, one volume protein extract was added to four volumes of the prewarmed $\left(25^{\circ} \mathrm{C}\right)$ reaction mixture containing $5 \mathrm{mM} \mathrm{KNO}_{3}$, $100 \mathrm{mM}$ HEPES-NaOH (pH 7.5), and $0.25 \mathrm{mM} \mathrm{NADH}$ and incubated at $25^{\circ} \mathrm{C}$ for $30 \mathrm{~min}$. The reaction was stopped by the addition of $0.1 \mathrm{M}$ zinc acetate and was allowed to stand for
$15 \mathrm{~min}$, followed by centrifugation at $12,000 \mathrm{~g}$ for $15 \mathrm{~min}$. After adding $1 \mathrm{ml}$ of $0.02 \%(\mathrm{v} / \mathrm{v}) \mathrm{N}$-(1-naphthyl)-ethylenediamine in distilled water plus $1 \mathrm{ml}$ of $1 \%(\mathrm{w} / \mathrm{v})$ sulfanilamide in $3 \mathrm{M} \mathrm{HCl}$, the production of nitrite was measured at $520 \mathrm{~nm}$. The enzyme quantity required for catalyzing $1 \mu \mathrm{mol} \mathrm{NO}{ }_{2}^{-}$within $1 \mathrm{~h}$ was calculated as one unit of NR. The spectrophotometric analyses were measured using UV-2700 spectrophotometer (Shimadzu, Kyoto, Japan) at room temperature. Each treatment had six biological replicates.

\section{Real-Time Quantitative Reverse Transcription PCR Analysis}

The transcript levels of NOA1, NIA-1, and NIA-2 were quantified by real-time quantitative reverse transcription PCR (RT-qPCR). The tobacco plant pretreatment was performed as described above. At 15 days after the removal of the adult whiteflies, the fourth leaf (nine to 10 nymphs $/ \mathrm{cm}^{2}$ ) was sampled for gene expression analysis. Total RNA was extracted using the EasyPure Plant RNA Kit (TransGen Biotechnology, Beijing, China). The first chain of cDNA was synthesized using the TransScript FirstStrand cDNA Synthesis Kit (TransGen Biotechnology, Beijing, China). The RT-qPCR was carried out on a Bio-Rad CFX96 Real-Time PCR System (Bio-Rad Laboratories, Hercules, CA, United States) with SYBR-Green detection. The average threshold cycle $\left(C_{t}\right)$ was calculated per sample. The comparative $2^{-\Delta \Delta C T}$ method was used to calculate the relative gene expression levels. The housekeeping gene Actin (Genbank accession no. X69885.1) was used as an internal reference. Each gene was analyzed in triplicate in each of the three biological replicates (the sampled plants were randomly selected). RT-qPCR Primers and gene accession numbers are indicated in Supplementary Table S1.

\section{The Effect of NO on B. tabaci Performance \\ Chemical Treatment}

Sodium nitroprusside or 2-(4-carboxyphenyl)- 4,4,5,5tetramethylimidazoline-1-oxyl-3-oxide (cPTIO) was prepared in distilled water to 350 and $200 \mu \mathrm{M}$ final concentrations, respectively, containing $0.02 \%(\mathrm{v} / \mathrm{v})$ Tween 20 . Tobacco seedlings with four true leaves were first pretreated with chemicals on their leaves. At $24 \mathrm{~h}$ after the treatment, the plants were used for the whitefly bioassay (below). Tobacco seedlings pretreated with double-distilled water served as no-chemical controls. Thereafter, the leaves of the plants were treated with SNP or cPTIO every 5 days after $B$. tabaci infestation. Each treatment had eight biological replicates.

\section{Virus-Induced Gene Silencing}

RNA extraction and cDNA synthesis were performed as described above. The construction of the NOA1-silencing vector was performed according to the method previously described by Luan et al. (2013). NOA1 nucleotide fragments (Genbank accession no. HM755675) were amplified using target-specific primers, and the PCR product was cloned into the pBIN2mDNA1 (BamHI-XbaI-digested) plasmid, and sequencing of the recombined vector was done to confirm the fidelity of the inserts. Electroporation was then used to transform 
the silencing-vector into EHA105 (Agrobacterium tumefaciens strain). The $A$. tumefaciens cultures $(0.2 \mathrm{ml}$, ABS600 = 0.6) carrying pBIN2mDNA1 (NOA1 fragment insert) were mixed with equal volumes of TbCSV (a helper virus), and the mixtures were infiltrated into the stem of each plant with four true leaves. The plants inoculated with A. tumefaciens cultures carrying pBIN2mDNA1 (without the gene insert) and TbCSV were treated as empty-vector control plants. All plants were grown and cultivated under the same conditions as described above. The second leaf from the top of the gene-silenced plants (fivetrue-leaf stage) was sampled for detection of the silencing efficiency using RT-qPCR. The Actin gene was used as an internal reference. NOA1-silenced and control plants were used for the whitefly bioassay (below). The primer pairs and the gene accession numbers used in this section are provided in Supplementary Table S1.

\section{Bemisia tabaci Preference and Performance}

Tobacco plant pretreatment was performed as described above (per the first paragraph of the section "The Effect of NO on B. tabaci Performance"). In the B. tabaci adult choice experiment, the treatment and the control plants were diagonally positioned in screened cages $(50 \mathrm{~cm} \times 50 \mathrm{~cm} \times 50 \mathrm{~cm})$, and 200 newly emerged adult whiteflies (female/male $=1: 1$ ) were placed into the center of the cage. After $72 \mathrm{~h}$, the amount of adult whiteflies on each plant was calculated. The plants with adult whiteflies were covered in transparent plastic foil and the number of whiteflies was counted in dim light to avoid disturbance and the relocation of the whiteflies. Each treatment (one cage with two plants) was replicated six times independently.

In the $B$. tabaci adult survival experiment, 20 newly emerged adult whiteflies were released into a leaf cage $(20 \mathrm{~mm}$ high, $80 \mathrm{~mm}$ diameter) attached to the stalk of the fourth leaf of chemically treated and control plants. The adult survival was consistently calculated from the average number of whiteflies per plant. Each treatment had eight biological replicates.

In the nymph $B$. tabaci development experiment, chemically treated or water-treated plants were placed in a screen cage $(25 \mathrm{~cm} \times 25 \mathrm{~cm} \times 25 \mathrm{~cm}$ ) (one plant per cage). About 100 newly emerged adult whiteflies (female/male ratio, approximately 1:1) were released into the cage and allowed to feed and oviposit on plants. They were removed from the plants by aspiration after $12 \mathrm{~h}$ of infestation and oviposition. After 20 days of adult whitefly infestation, the proportion of nymphs (first to fourth instars) was calculated on each plant to estimate the developmental rate. Each treatment had eight biological replicates.

\section{The Causal Relationship Between NO Production and JA-Mediated Defense Pathway Quantification of Endogenous JA}

Chemical treatment and NOA1 silencing were performed as described above. Leaves from infested and control plants were sampled at $0,5,10,15$, and 20 days after the removal of adults. Endogenous JA content was determined using an enzyme-linked immunosorbent assay (ELISA) according to
Yang et al. (2001). The antibodies used in the ELISA test were supplied by Phytohormones Research Institute (China Agricultural University, Beijing, China). In brief, $0.2 \mathrm{~g}$ fresh tobacco leaves was extracted for $24 \mathrm{~h}$ at $4^{\circ} \mathrm{C}$ and then purified by passing through C18 Sep-Pak cartridges (Thermo, United States). The microtitration plates were coated with $50 \mu \mathrm{l}$ sample and $50 \mu \mathrm{l}$ antigen $\left(0.25 \mu \mathrm{g} \mathrm{ml}^{-1}\right)$ against the JA hormones. The coated plates were then incubated for $45 \mathrm{~min}$ at $37^{\circ} \mathrm{C}$. Next, each well was filled with $100 \mu \mathrm{l}$ antibodies $\left(20 \mu \mathrm{g} \mathrm{ml}^{-1}\right)$ and incubated for another $1 \mathrm{~h}$ at $37^{\circ} \mathrm{C}$. Finally, $100 \mu \mathrm{l}$ color-appearing solution containing $2 \mathrm{mg} \mathrm{ml}^{-1} \mathrm{O}$-phenylenediamine and $0.008 \%$ (v) $\mathrm{H}_{2} \mathrm{O}_{2}$ was added to each well. The plates were incubated for $15 \mathrm{~min}$ at $37^{\circ} \mathrm{C}$ in the dark, and the reactions were subsequently terminated using $50 \mu \mathrm{l}$ of $2 \mathrm{M} \mathrm{H}_{2} \mathrm{SO}_{4}$ per well. The absorbance was recorded at $490 \mathrm{~nm}$. Each concentration was analyzed in triplicate in each of the three biological replicates per sampling date (each plant was sampled once).

\section{JA-Related Gene Expression}

Chemical treatment and NOA1 silencing were performed as described above. At 15 days after the removal of the adult whiteflies, the fourth leaf $\left(9-10\right.$ nymphs $\left./ \mathrm{cm}^{2}\right)$ was sampled for gene expression analysis. The transcript levels of $L O X 3, A O C$, TPI, and PI-II were quantified by RT-qPCR. Actin (Genbank accession no. X69885.1) was used as the internal reference for RT-qPCR analysis. Each gene was analyzed in triplicate in each of three biologically independent treatments. The RTqPCR primers and gene accession numbers are indicated in Supplementary Table S1.

\section{Statistical Analysis}

Statistical significance in hormone contents, enzyme levels, gene expression, and adult whitefly performance was tested using analysis of variance (ANOVA), followed by Tukey's test at a significance level of $5 \%(P<0.05)$. The $B$. tabaci adult survival was assayed using a Cox proportional hazards model. The general linear model was used to analyze the univariate percentage of the fourth instars of B. tabaci on different plants. All data in the present study were analyzed using the statistical software package SPSS version 24.0 (SPSS, Chicago, United States).

\section{RESULTS}

\section{Effect of B. tabaci Infestation on NO Biosynthesis}

Feeding of $B$. tabaci caused a significant accumulation of NO, which was $53.41 \%$ higher than in the control at day 15 (MEAM1: $P<0.001$; time: $P<0.001$; interaction: $P=0.033$, Figure 1A). Simultaneously, leaves infested with $B$. tabaci showed a greater fluorescence intensity compared with the uninfested controls (Figure 1B). However, the NR activity (MEAM1: $P=0.373$; time: $P=0.260$; interaction: $P=0.878)$ and transcript levels of NIA$1(t=0.641 ; d f=3.397 ; P=0.562)$ and NIA-2 $(t=-1.110$; $d f=3.877 ; P=0.331)$ did not show obvious alterations during the entire feeding period compared with the uninfested controls (Figures 1C,D), whereas the transcript levels of NOA1 increased, 

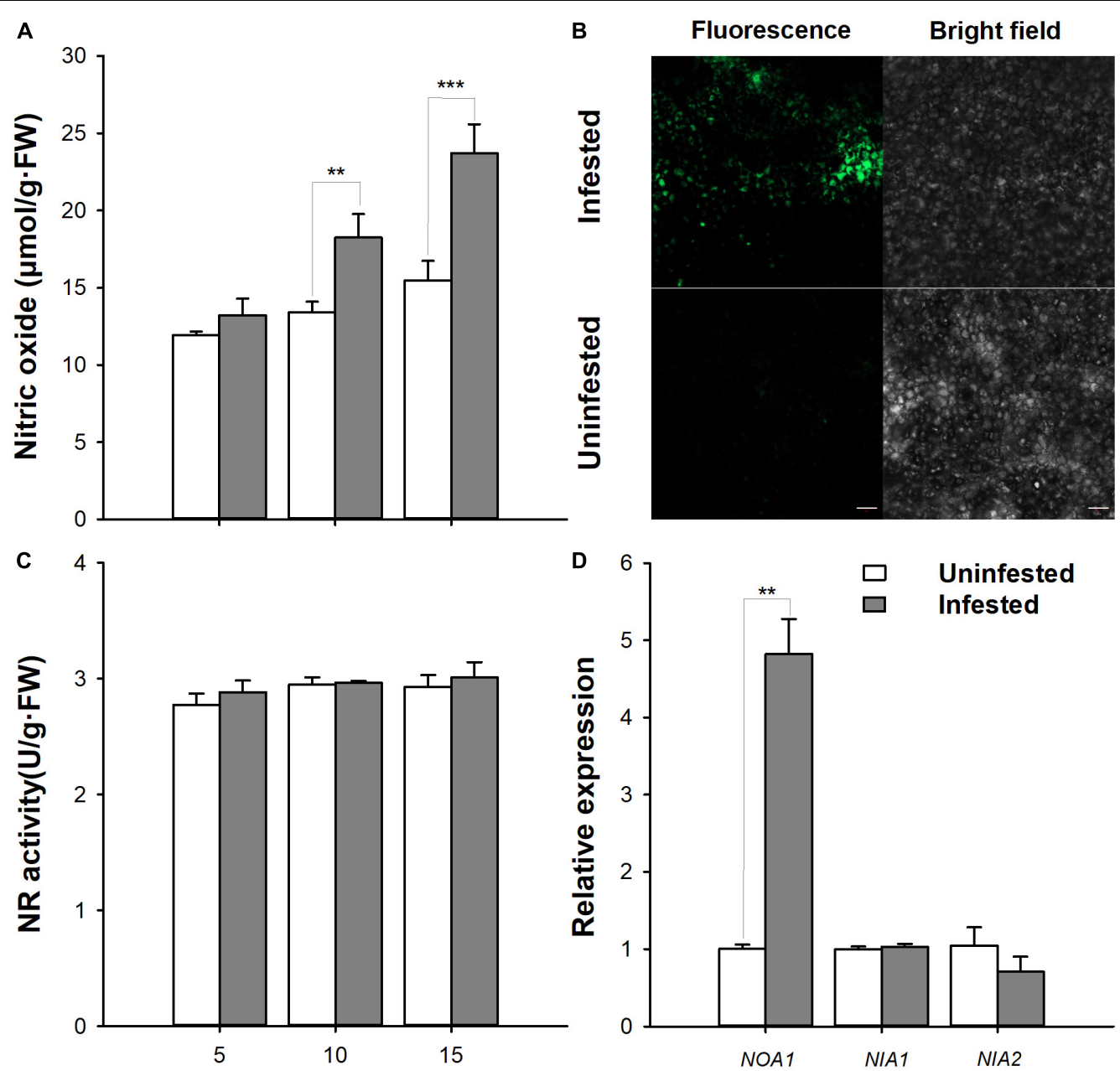

B. tabaci infestation (days)

Genes involved in NO biosynthesis

FIGURE 1 | Quantification of nitric oxide (NO) levels, NO synthase activities, and gene expression in Bemisia tabaci nymph-infested tobacco plants. (A) NO production was determined by spectrophotometry after $B$. tabaci nymph infestation. (B) NO production was estimated using the fluorescence indicator 4-amino-5-methylamino-2', $7^{\prime}$-difluorofluorescein diacetate after B. tabaci nymph infestation. (C) NR activity levels in tobacco plants infested with B. tabaci nymphs. (D) NOA1, NIA1, and NIA2 expression levels in tobacco plants infested with B. tabaci nymphs. Bar $=50 \mu \mathrm{m}$. The values are means ( \pm E) of six biological replicates. The asterisks above the bars indicate significant differences $\left(* * P<0.05\right.$, $\left.{ }^{* * *} P<0.001\right)$.

being 4.82-fold ( $t=8.321 ; d f=8.321 ; P=0.013$ ) higher than that of the uninfested control at day 15 (Figure 1D). These data indicate that $B$. tabaci infestation could trigger the NO signaling pathway in tobacco plants.

\section{The Effect of NO on B. tabaci Performance}

Chemical application altered the settling preference of B. tabaci adults. Compared with the water-treated plants, $71.09 \%$ $(P<0.001)$ of adults settled on the plants treated with SNP, whereas only $28.9 \%(P=0.01)$ of adults settled on the plants applied with cPTIO (Figure 2A). Furthermore, at 20 days post-infestation, the nymph development rate differed on the SNP-, cPTIO-, and water-treated plants. The fourth instar proportion in SNP-treated plants was $14.11 \%$ higher than that in watered-treated control plants $(P<0.01)$. On the contrary, the fourth instar proportion in cPTIO-treated plants was significantly lower than that in watered-treated control plants $(P<0.01$, Figure $2 B)$. However, the survival rate of adult whiteflies did not differ on plants with different chemical applications $(P>0.05$, Figure 2C).

Furthermore, the NO synthesis-related gene NOA1 was silenced using the virus-induced gene silencing technique. As shown in the results, the transcript levels of NOA1 and NO decreased by 0.634 -fold $(F=6.668 ; d f=2.8 ; P=0.005)$ and $51.9 \%$ $(F=16.256 ; d f=2.18 ; P=0.021)$, respectively, in NOA1-silenced plants after 15 days of $B$. tabaci infestation compared with the control (Figure 3A). Similar to cPTIO application, NOA1 silencing decreased the performance of B. tabaci. Compared with the empty vector-injected plants, $68.77 \%(P=0.001)$ of adults settled on the NOA1-silenced plants, and the fourth instar 


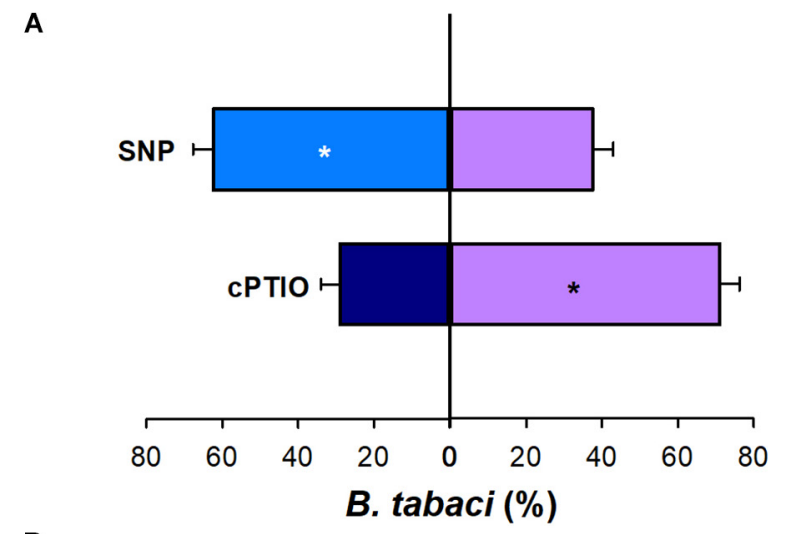

B
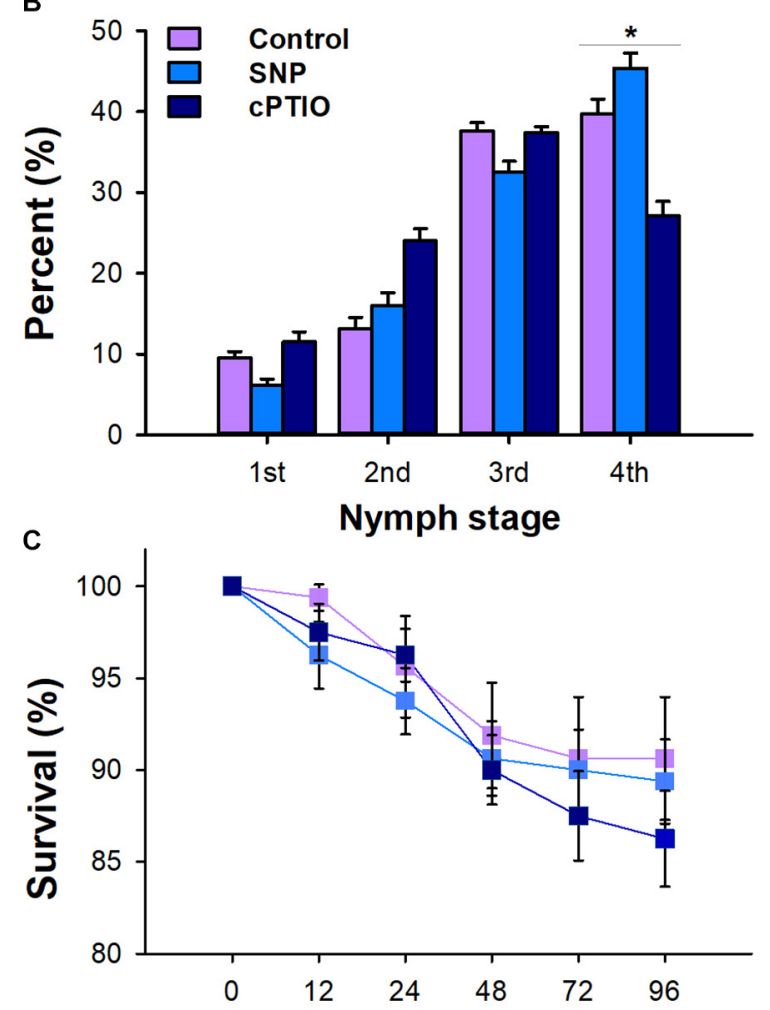

B. tabaci infestation (hour)

FIGURE 2 | Effect of 2-(4-carboxypheny)-

4,4,5,5-tetramethylimidazoline-1-oxyl-3-oxide (CPTIO) and sodium nitroprusside (SNP) application on B. tabaci performance. (A) Settling preference of adult whiteflies on CPTIO- and SNP-treated plants. The values are means $( \pm \mathrm{SE})$ of six biological replicates. (B) The percentage of nymph whiteflies in each instar on CPTIO- and SNP-treated plants at 20 days after the adults were removed. (C) Survival of adult whiteflies on CPTIO- and SNP-treated plants. The values are means $( \pm \mathrm{SE})$ of eight biological replicates. The asterisks above the bars indicate significant differences $\left({ }^{*} P<0.05\right)$.

proportion in the NOA1-silenced plants was significantly lower than that of the empty vector-injected control plants $(P<0.01$, Figures 3B,C). However, NOA1 silencing had no significant effect on the adult survival rate $(P>0.05$, Figure $3 \mathrm{D})$. These data indicate that a positive correlation exists between the NO level and B. tabaci.

\section{The Causal Relationship Between NO Production and JA-Mediated Defense Pathway}

Bemisia tabaci nymph infestation has no significant effect on JA content in the leaves of water-treated plants compared with that of the uninfested controls $(P>0.05)$. However, the JA content was obviously higher in the leaves with $\mathrm{CPTIO}$ application than in the leaves of watered-treated controls at 0-20 days after B. tabaci infestation. Furthermore, the JA content peaked at 15 days, at which point it was $61.37 \%(F=32.112 ; d f=2.26 ; P<0.001)$ higher than that of the uninfested control plants (Figure 4A). In response to $B$. tabaci infestation, the variation in $A O C(F=7.309$; $d f=2.8 ; P=0.221)$ and $\operatorname{LOX} 3(F=9.467 ; d f=2.8 ; P=0.996)$ transcript levels did not differ between the water- and CPTIOtreated plants. However, the transcript levels of $P I-I I(F=20.624$; $d f=2.8 ; P=2760.514)$ and TPI $(F=13.734 ; d f=2.8 ; P=0.169)$ were not significantly affected in the water-treated plants but were increased by 2.256-fold $(F=20.624 ; d f=2.8 ; P=0.007)$ and 1.315 -fold $(F=13.734 ; d f=2.8 ; P<0.05)$, respectively, in the cPTIO-treated plants following B. tabaci infestation (Figure 4B).

Similar to cPTIO application, B. tabaci nymph infestation obviously impacted JA accumulation in NOA1-silenced plants. The JA content was substantially higher in the leaves of the B. tabaci-infested NOA1-silenced plants than in the uninfested empty-vector controls at 0-20 days after infestation. Furthermore, the JA content peaked at 15 days, at which point it was $83.07 \%(F=130.216 ; d f=2.26 ; P<0.001)$ higher than that of the uninfested control plants (Figure 4C). In response to B. tabaci infestation, the variation in $A O C(F=34.376 ; d f=2.8$; $P=0.221)$ and $\operatorname{LOX} 3(F=188.103 ; d f=2.8 ; P=0.996)$ transcript levels did not differ between the empty-vector-injected and the NOA1-silenced plants. However, the transcript levels of $P I-I I$ and TPI were decreased by 0.408 -fold $(F=26.966 ; d f=2.8 ; P=0.036)$ and 0.591 -fold $(F=263.591 ; d f=2.8 ; P<0.001)$, respectively, in the empty vector-injected plants but were increased by 1.468 fold $(F=26.966 ; d f=2.8 ; P=0.017)$ and 1.5 -fold $(F=263.591$; $d f=2.8 ; P<0.001)$, respectively, in the NOA1-silenced plants following $B$. tabaci infestation (Figure 4D). These results indicate that the application of CPTIO and NOA 1 silencing could partially alleviate the suppression of the JA-dependent defensive response mediated by B. tabaci infestation.

\section{DISCUSSION}

\section{Bemisia tabaci Infestation Can Trigger NO Signaling in Tobacco Plants}

Interacting with insects for 420 million of years has led plants to evolve sophisticated defensive responses to fend off these invertebrate herbivores. Vice versa, insects have also evolved complex counter-defense systems for their survival, and the manipulation of plant defense signaling pathways is one of the most effective approaches (Zhang et al., 2013a). NO is 


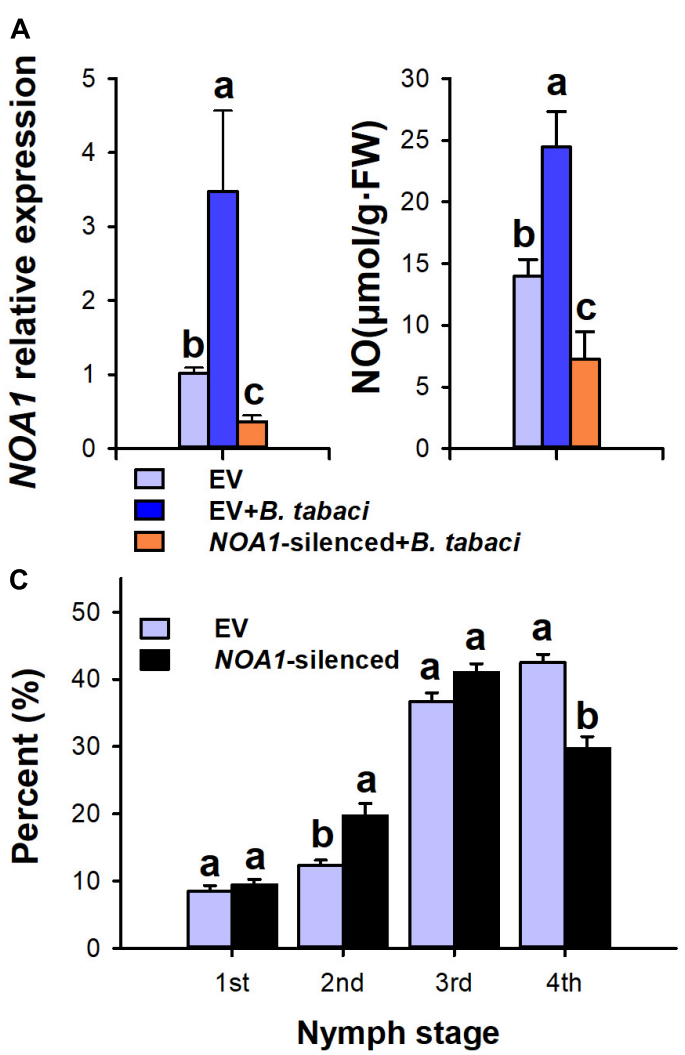

B

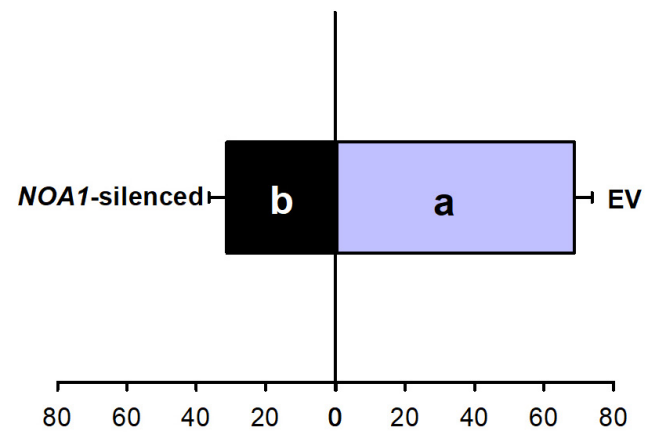

B. tabaci $(\%)$

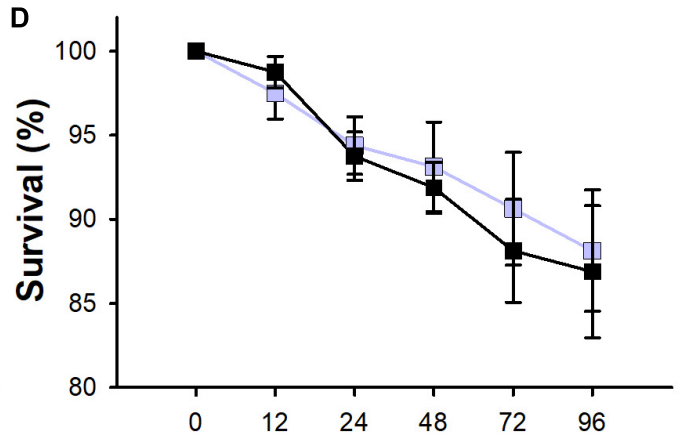

B. tabaci infestation (hours)

FIGURE 3 | Bemisia tabaci performance on NOA1-silenced tobacco plants. (A) Nitric oxide content and NOA1 transcript levels in NOA1-silenced tobacco plants after $B$. tabaci infestation. The values are means ( \pm SE) of three biological replicates. (B) Settling preference of adult whiteflies on NOA1-silenced tobacco plants. The values are means $( \pm$ SE) of six biological replicates. (C) The percentage of nymph whiteflies in each instar on NOA1-silenced plants at 20 days after the adults were infested. (D) Survival of adult whiteflies on NOA1-silenced tobacco plants. The values are means ( \pm SE) of eight biological replicates. The different letters above the bars indicate values that are significantly different $(P<0.05)$.

one of the major plant defense signaling molecules that act in complex networks (González et al., 2012; Caarls et al., 2015). In this study, biochemical and confocal data show that NO levels were significantly increased following $B$. tabaci nymph infestation. Additionally, NOA1 expression was consistent with that of the NO level. NOA1 (NO-associated protein 1), a cGTPase, is primarily involved in ribosome assembly in plants and affects the accumulation of NO indirectly (Gas et al., 2009; Van Ree et al., 2011). These results indicated that the infestation of $B$. tabaci nymphs could trigger the NO signaling pathway in tobacco plants. Generally, NR and NOS are two major enzymatic pathways proposed for NO formation in plants (Rockel et al., 2002; Malik et al., 2011). However, in the present study, the NR activity and the NIA-1 and NIA-2 transcript levels were unaffected by B. tabaci infestation. It is now firmly evidenced that embryophytes do not possess canonical NOS (Santolini et al., 2017; Astier et al., 2018), even though putative NOS-like enzymes have been detected in some studies (Delledonne et al., 1998; Morot-Gaudry-Talarmain et al., 2002). Collectively, there is not a close relationship between NR or NOS-like enzyme and B. tabacielicited NO generation in tobacco leaves. Plants have many routes for synthesizing NO besides NR and NOS; several enzymes, including xanthine oxidoreductase, horseradish peroxidase, and catalase, are suspected to have the ability to produce NO in addition to their primary enzymatic activities (Jeandroz et al., 2016). Interestingly, the effect of $B$. tabaci infestation on NO signaling varied with feeding time. The NO-related indexes did not differ obviously from the controls until 10 days following infestation. This may be because the third nymphal instars stimulate the host plants more greatly (Estrada-Hernández et al., 2009; Wang et al., 2010).

\section{NO Signaling Is Positively Correlated With B. tabaci Performance}

As a crucial signaling molecule, NO has been associated with the induced plant defensive response to phloem feeder stress. For instance, foliar treatment with NO donors induced defense reactions against the pea aphid, $A$. pisum, and the green peach aphid, M. persicae, in pea and sweet pepper plants (Woźniak et al., 2017; Kim et al., 2018). In our bioassay, exogenous NO donor SNP treatment significantly increased the oviposition preference of whitefly adults and accelerated the nymphal development in tobacco plants. Conversely, spraying cPTIO, a NO scavenger, on tobacco leaves rendered it more resistant to whiteflies. The performance of both adult and nymph whitefly was significantly 

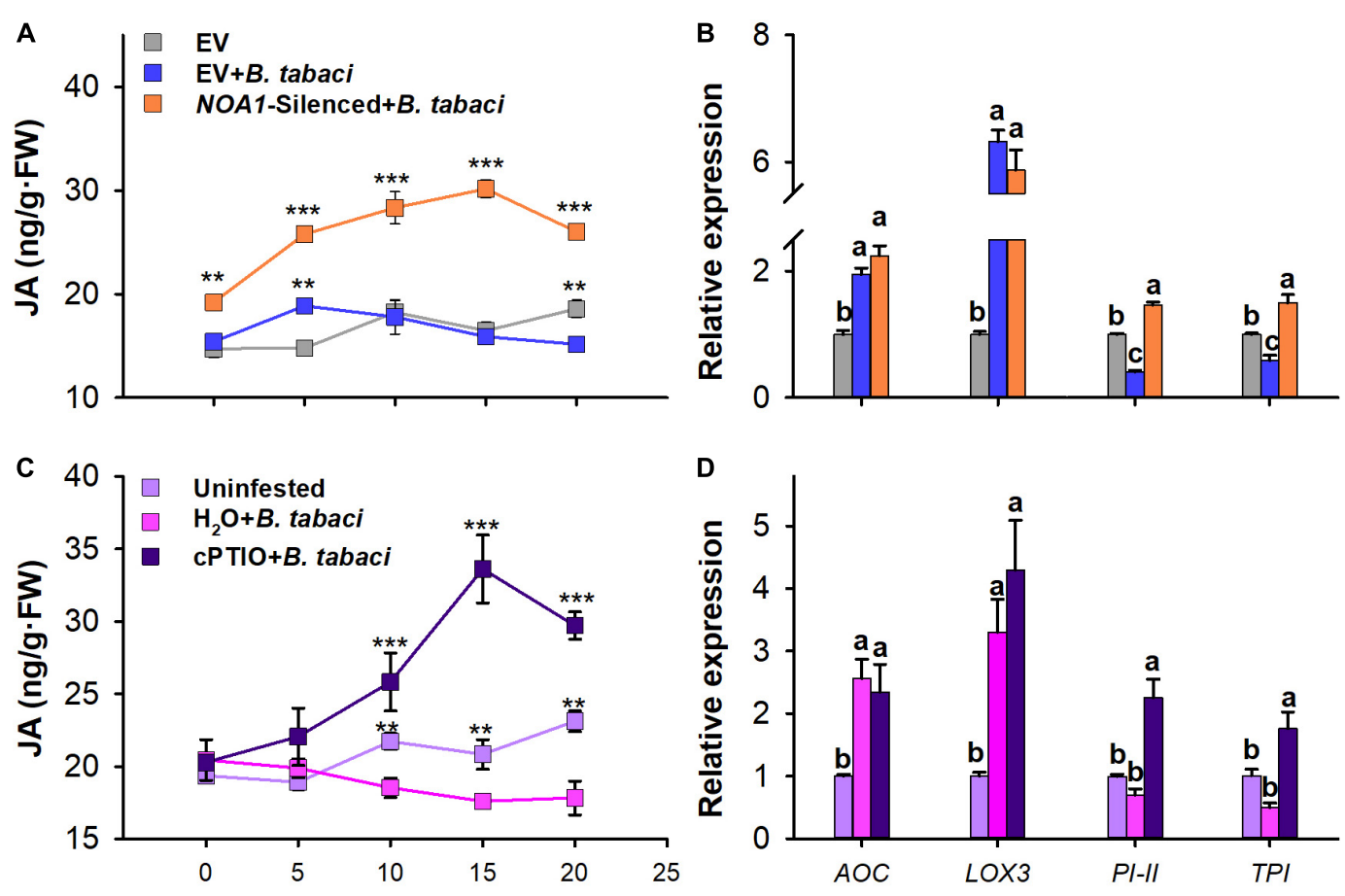

B. tabaci infestation (day)

JA-related defense genes

FIGURE 4 | Quantification of jasmonic acid (JA) levels and expression of JA-related genes in B. tabaci nymph-infested tobacco plants. Jasmonic acid levels and expression of JA-related genes in NOA1-silenced (A,B) and 2-(4-carboxyphenyl)- 4,4,5,5-tetramethylimidazoline-1-oxyl-3-oxide-treated (C,D) tobacco plants after B. tabaci infestation. The values are means $( \pm \mathrm{SE})$ of three biological replicates. The asterisks above the bars indicate significant differences $(* * P<0.05$,

$\left.{ }^{* * *} P<0.001\right)$. The different letters above the bars indicate values that are significantly different $(P<0.05)$.

decreased in cPTIO-treated plants. Consistent with the effect of cPTIO treatment, silencing of NOA1 significantly decreased the production of $\mathrm{NO}$, thus enhancing tobacco's resistance to B. tabaci. In line with our results, B. tabaci performance is somewhat increased in sweet pepper after the application of NO aqueous solution (Kim et al., 2018). Wünsche et al. (2011a) found that the irNaNOA1 tobacco plants with lower NO contents are more resistant to $M$. sexta (Wünsche et al., 2011a). These results indicate that, unlike the adverse effect on phloem feeder aphids, a positive correlation exists between the NO level and whitefly performance. In addition, previous studies showed that B. tabaci infestation render the tobacco plants more resistant to subsequent $M$. persicae (Xue et al., 2010; Zhang X. et al., 2015; Zhang et al., 2017). Collectively, we suspected that triggering NO signaling allows $B$. tabaci to both enhance their performance and also defeat other competitors, which contribute to its outbreak.

\section{Bemisia tabaci-Induced NO Production Suppresses JA-Dependent Basal Response}

It has long been demonstrated that JA is involved in plant defense to whitefly in tomato and A. thaliana (Zarate et al., 2007; Luan et al., 2013; Zhang et al., 2018). The present lines of evidence suggest that a close association exists between NO and JA-mediated defense (Huang et al., 2004; Mur et al., 2013).
In the present research, infestation of $B$. tabaci suppressed the synthesis of JA and significantly decreased the transcript level of the downstream JA-responsive genes TPI and PI-II. This is consistent with the previous results that feeding by whiteflies suppresses downstream JA signaling defense genes in A. thaliana (Zhang et al., 2013b). However, cPTIO application or NOA1 silencing alleviated the suppression of JA levels and these defense genes. In line with our findings, irNOA1 tobacco plants show significantly higher JA levels than wild-type plants after treatment with $M$. sexta oral secretion (Wünsche et al., 2011a). The trend of JA defensive responses was consistent with that of the whitefly performance in cPTIO-treated and NOA1-silenced plants. In this way, we think that the $B$. tabaci-mediated activation of NO signaling led to the suppression of effectual JA defensive responses in tobacco plants. Similarly, NO donors SNP and SNAP treatment suppresses the expression of the JA-mediated defense gene $P I$ in the tomato plants (Orozco-Cárdenas and Ryan, 2002). However, in tomato plants, NO can enhance the JAdependent defensive response against root-knot nematode (Zhou et al., 2015). This was possibly due to the high complexity of the induced plant defense reactions which may vary with the host plant species.

Nitric oxide mediated $S$-nitrosylation can affect the function of many proteins (Malik et al., 2011; Mur et al., 2013). In this study, NO-dependent post-translational modification may be a crucial explanation for the suppression of JA defense 
responses. In RT-qPCR analysis, $B$. tabaci infestation induced the upstream JA-responsive genes AOC and LOX3 but suppressed JA synthesis and downstream JA-responsive genes. Additionally, the application of $\mathrm{CPTIO}$ and NOA 1 both silenced the partially alleviated $B$. tabaci-mediated suppression of JA signaling. These results are consistent with previous studies showing that while $\mathrm{NO}$ increases the expression of JA biosynthetic genes, including LOX3, AOC3, and OPR3 (Mur et al., 2012; Hussain et al., 2016), the activity of the intermediate JA biosynthetic enzyme, $A O C$, can be negatively affected by NO-mediated $S$-nitrosylation (Romero-Puertas et al., 2008). Thus, we suspected that B. tabaci infestation suppressed the JA signal pathway in a NO-dependent post-translational modification manner. Orozco-Cárdenas and Ryan (2002) found that NO appears to be directly associated with the wounding signaling pathway downstream of the JA pathway in tomato plants through $S$-nitrosylation (OrozcoCárdenas and Ryan, 2002). Silencing of GSNOR1, a nitrosylation scavenger, can enhance NO formation and decrease tobacco JA accumulation (Wünsche et al., 2011b). Furthermore, NO can act synergistically with SA-regulated responses as silencing NOA1 can decrease the expression of $P R 1$, a marker gene of the SA pathway (Asai and Yoshioka, 2009). In Arabidopsis and tomato plants, B. tabaci inhibited the expression of the JA-dependent defense gene by activating SA signaling (Zarate et al., 2007; Van der Does et al., 2013; Zhang et al., 2013b). The control of the transcriptional reprogramming of JA-induced genes by SA has been well established (Caarls et al., 2015). Recent findings have proved that NO-mediated $S$-nitrosylation can increase the affinity of cognate promoters in TGA-class transcription factors, which can bind to the ORA59, thereby suppressing JA-dependent defenses (Mur et al., 2013; Van der Does et al., 2013). Thus, NO may suppress JA-dependent defensive responses in a SAdependent manner.

\section{Summary and Perspectives}

Feeding of $B$. tabaci can manipulate the plant defense system, which constitutes one of the major factors contributing to its outbreak. NO is a crucial signaling molecule that is involved in numerous plant bioprocesses and performs sophisticated crosstalk with other plant hormones such as JA and SA. The data from this study verified our hypothesis that NO signaling is correlated with whitefly performance but is negatively correlated with JA-related defense responses. Feeding by B. tabaci suppressed the JA pathway and thereby enhanced its performance in a NO-dependent manner. Transcription factors can be affected by NO via S-nitrosylation in which $\mathrm{NO}$ acts as a mediator of plant defense signaling pathways. However, this study has

\section{REFERENCES}

Asai, S., and Yoshioka, H. (2009). Nitric oxide as a partner of reactive oxygen species participates in disease resistance to necrotrophic pathogen Botrytis cinerea in Nicotiana benthamiana. Mol. Plant Microbe Int. 22, 619-629. doi: 10.1094/MPMI-22-6-0619

Astier, J., Gross, I., and Durner, J. (2018). Nitric oxide production in plants: an update. J. Exp. Bot. 69, 3401-3411. doi: 10.1093/jxb/erx420 insufficient evidence to determine that $B$. tabaci suppresses the JA defense in this post-translational modification manner. Future investigations need to explore this crosstalk at the posttranslation level and to identify $S$-nitrosylated target protein in JA signaling, which will help to acquire new knowledge in MEAM1-plant interaction and provide insights for developing new methods to control this pest.

\section{DATA AVAILABILITY STATEMENT}

The datasets generated for this study can be found in the online repositories. The names of the repository/repositories and accession number(s) can be found below: 10.6084/m9.figshare.118 28283.

\section{AUTHOR CONTRIBUTIONS}

MX and HZ designed the experiments. YX, CQ, and XS conducted the experiments. YX, CQ, ZJ, and XZ analyzed and interpreted the data. $\mathrm{YX}, \mathrm{HZ}$, and $\mathrm{XZ}$ drafted and revised the manuscript. All the authors read and approved the final manuscript.

\section{FUNDING}

This work was financially supported by the National Natural Science Foundation of China (31701799) and Shandong Modern Agricultural Industry Technology System (SDAIT05-022-08).

\section{ACKNOWLEDGMENTS}

The authors are grateful to the Department of Plant Pathology, Nanjing Agricultural University, for providing tobacco seeds and gene silencing vectors and all the members of the Plant Disease Prevention Laboratory for technical assistance. The authors also thank the reviewers for their constructive comments and suggestions.

\section{SUPPLEMENTARY MATERIAL}

The Supplementary Material for this article can be found online at: https://www.frontiersin.org/articles/10.3389/fphys. 2020.00847/full\#supplementary-material

Baudouin, E. (2011). The language of nitric oxide signalling. Plant Biol. 13, 233-242. doi: 10.1111/j.1438-8677.2010.00403.x

Caarls, L., Pieterse, C. M., and Van Wees, S. (2015). How salicylic acid takes transcriptional control over jasmonic acid signaling. Front. Plant Sci. 6:170. doi: $10.3389 /$ fpls. 2015.00170

Corpas, F. J., Leterrier, M., Valderrama, R., Airaki, M., Chaki, M., Palma, J. M., et al. (2011). Nitric oxide imbalance provokes a nitrosative response in plants under abiotic stress. Plant Sci. 181, 604-611. doi: 10.1016/j.plantsci.2011.04.005 
Delledonne, M., Xia, Y., Dixon, R. A., and Lamb, C. (1998). Nitric oxide functions as a signal in plant disease resistance. Nature 394, 585-588. doi: 10.1038/29087

Drzewiecka, K., Jeleñ, H., Narożna, D., Ruciñska-Sobkowiak, R., Kêsy, J., Floryszak-Wieczorek, J., et al. (2014). Differential induction of Pisum sativum defense signaling molecules in response to pea aphid infestation. Plant Sci. 221, 1-12. doi: 10.1016/j.plantsci.2014.01.011

Estrada-Hernández, M. G., Valenzuela-Soto, J. H., Ibarra-Laclette, E., and DélanoFrier, J. P. (2009). Differential gene expression in whitefly Bemisia tabaciinfested tomato (Solanum lycopersicum) plants at progressing developmental stages of the insect's life cycle. Physiol. Plantarum 137, 44-60. doi: 10.1111/j. 1399-3054.2009.01260.x

Feeny, P. (1976). "Plant apparency and chemical defense. Biochemical interaction between plants and insects," in Proceedings of the Fifteenth Annual Meeting of the Phytochemical Society of North America, New York, NY: Plenum Press.

Fröhlich, A., and Durner, J. (2011). The hunt for plant nitric oxide synthase (NOS): is one really needed? Plant Sci. 181, 401-404. doi: 10.1016/j.plantsci.2011.07. 014

Gas, E., Flores-Pérez, Ú, Sauret-Güeto, S., and Rodríguez-Concepción, M. (2009). Hunting for plant nitric oxide synthase provides new evidence of a central role for plastids in nitric oxide metabolism. Plant Cell 21, 18-23. doi: 10.1111/17447917.12576

González, A., de Los Ángeles Cabrera, M., Henríquez, M. J., Contreras, R. A., Morales, B., and Moenne, A. (2012). Cross talk among calcium, hydrogen peroxide, and nitric oxide and activation of gene expression involving calmodulins and calcium-dependent protein kinases in Ulva compressa exposed to copper excess. Plant Physiol. 158, 1451-1462. doi: 10.1104/pp.111.191759

Gupta, K. J., Fernie, A. R., Kaiser, W. M., and van Dongen, J. T. (2011). On the origins of nitric oxide. Trends Plant Sci. 16, 160-168. doi: 10.1016/j.tplants.2010. 11.007

Huang, X., Stettmaier, K., Michel, C., Hutzler, P., Mueller, M. J., and Durner, J. (2004). Nitric oxide is induced by wounding and influences jasmonic acid signaling in Arabidopsis thaliana. Planta 218, 938-946. doi: 10.1007/s00425003-1178-1

Hussain, A., Mun, B. G., Imran, Q. M., Lee, S. U., Adamu, T. A., Shahid, M., et al. (2016). Nitric oxide mediated transcriptome profiling reveals activation of multiple regulatory pathways in Arabidopsis thaliana. Front. Plant Sci. 7:975. doi: $10.3389 /$ fpls.2016.00975

Inbar, M., Doostdar, H., and Mayer, R. T. (1999). Effects of sessile whitefly nymphs (Homoptera: Aleyrodidae) on leaf-chewing larvae (Lepidoptera: Noctuidae) Environ. Entomol. 28, 353-357. doi: 10.1093/ee/28.3.353

Jeandroz, S., Wipf, D., Stuehr, D. J., Lamattina, L., Melkonian, M., Tian, Z., et al. (2016). Occurrence, structure, and evolution of nitric oxide synthase-like proteins in the plant kingdom. Sci. Signal. 9:re2. doi: 10.1126/scisignal.aad4403

Kaplan, I., and Denno, R. F. (2007). Interspecific interactions in phytophagous insects revisited: a quantitative assessment of competition theory. Ecol. Lett. 10, 977-994. doi: 10.1111/j.1461-0248.2007.01093.x

Kempema, L. A., Cui, X., Holzer, F. M., and Walling, L. L. (2007). Arabidopsis transcriptome changes in response to phloem-feeding silverleaf whitefly nymphs. Similarities and distinctions in responses to aphids. Plant Physiol. 143, 849-865. doi: 10.1104/pp.106.090662

Kim, S., Lee, J. K., Song, Y.-J., Kang, S. C., Kim, B., Choi, I. J., et al. (2018). Evaluating natural compounds as potential insecticides against three economically important pests, Bemisia tabaci (Hemiptera: Aleyrodidae), Frankliniella occidentalis (Thysanoptera: Thripidae), and Myzus persicae (Hemiptera: Aphididae), on greenhouse sweet peppers. Appl. Biol. Chem. 61, 313-323. doi: 10.1007/s13765-018-0362-8

Kwan, Y. M., Meon, S., Ho, C. L., and Wong, M. Y. (2015). Cloning of nitric oxide associated 1 (NOA1) transcript from oil palm (Elaeis guineensis) and its expression during Ganoderma infection. J. Plant Physiol. 174, 131-136. doi: 10.1016/j.jplph2014.10.003

Liang, P., Cui, J. Z., Yang, X. Q., and Gao, X. W. (2007). Effects of host plants on insecticide susceptibility and carboxylesterase activity in Bemisia tabaci biotype B and greenhouse whitefly. Trialeurodes vaporariorum. Pest Manag. Sci. 63, 365-371. doi: 10.1002/ps.1346

Liu, S. S., De Barro, P., Xu, J., Luan, J. B., Zang, L. S., Ruan, Y. M., et al. (2007). Asymmetric mating interactions drive widespread invasion and displacement in a whitefly. Science 318, 1769-1772. doi: 10.1126/science.1149887
Locato, V., Paradiso, A., Sabetta, W., De Gara, L., and de Pinto, M. C. (2016). Nitric oxide and reactive oxygen species in PCD signaling. Adv. Bot. Res. 77, 165-192. doi: 10.1016/bs.abr.2015.10.008

Luan, J. B., Ghanim, M., Liu, S. S., and Czosnek, H. (2013). Silencing the ecdysone synthesis and signaling pathway genes disrupts nymphal development in the whitefly. Insect Biochem. Molec. 43, 740-746. doi: 10.1016/j.ibmb.2013. 05.012

Luan, J. B., Jing, X., Lin, K. K., Zalucki, M. P., and Liu, S.-S. (2012). Species exclusion between an invasive and an indigenous whitefly on host plants with differential levels of suitability. J. Integr. Agr. 11, 215-224. doi: 10.1016/s20953119(12)60006-9

Malik, S. I., Hussain, A., Yun, B. W., Spoel, S. H., and Loake, G. J. (2011). GSNOR-mediated de-nitrosylation in the plant defence response. Plant Sci. 181, 540-544. doi: 10.1016/j.plantsci.2011.04.004

Mayer, R. T., Inbar, M., McKenzie, C., Shatters, R., Borowicz, V., Albrecht, U., et al. (2002). Multitrophic interactions of the silverleaf whitefly, host plants, competing herbivores, and phytopathogens. Arch. Insect Biochem. 51, 151-169. doi: 10.1002/arch.10065

McKenzie, C., Shatters, R. G. Jr., Doostdar, H., Lee, S., Inbar, M., and Mayer, R. T. (2002). Effect of geminivirus infection and Bemisia infestation on accumulation of pathogenesis-related proteins in tomato. Arch. Insect Biochem. 49, 203-214. doi: $10.1002 /$ arch. 10020

Moloi, M., van der Westhuizen, A., and Jankielsohn, A. (2015). Nitric oxide is an upstream signal involved in the multisignalling network during the Russian wheat aphid resistance response and its application enhances resistance. Cereal Res. Commun. 43, 29-40. doi: 10.1556/CRC.2014.0018

Morot-Gaudry-Talarmain, Y., Rockel, P., Moureaux, T., Quillere, I., Leydecker, M., Kaiser, W., et al. (2002). Nitrite accumulation and nitric oxide emission in relation to cellular signaling in nitrite reductase antisense tobacco. Planta 215, 708-715. doi: 10.1007/s00425-002-0816-3

Mur, L. A., Prats, E., Pierre, S., Hall, M. A., and Hebelstrup, K. H. (2013). Integrating nitric oxide into salicylic acid and jasmonic acid/ethylene plant defense pathways. Front. Plant Sci. 4:215. doi: 10.3389/fpls.2013.00215

Mur, L. A., Sivakumaran, A., Mandon, J., Cristescu, S. M., Harren, F. J., and Hebelstrup, K. H. (2012). Haemoglobin modulates salicylate and jasmonate/ethylene-mediated resistance mechanisms against pathogens. J. Exp. Bot. 63, 4375-4387. doi: 10.1093/jxb/ers116

Orozco-Cárdenas, M. L., and Ryan, C. A. (2002). Nitric oxide negatively modulates wound signaling in tomato plants. Plant Physiol. 130, 487-493. doi: 10.1104/pp. 008375

Pieterse, C. M., Van der Does, D., Zamioudis, C., Leon-Reyes, A., and Van Wees, S. C. (2012). Hormonal modulation of plant immunity. Annu. Rev. Cell Dev. Bi. $28,489-521$.

Reymond, P., and Farmer, E. E. (1998). Jasmonate and salicylate as global signals for defense gene expression. Curr. Opin. Plant Biol. 1, 404-411. doi: 10.1016/ s1369-5266(98)80264-1

Rockel, P., Strube, F., Rockel, A., Wildt, J., and Kaiser, W. M. (2002). Regulation of nitric oxide $(\mathrm{NO})$ production by plant nitrate reductase in vivo and in vitro. J. Exp. Bot. 53, 103-110. doi: 10.1093/jexbot/53.366.103

Romero-Puertas, M. C., Campostrini, N., Mattè, A., Righetti, P. G., Perazzolli, M., Zolla, L., et al. (2008). Proteomic analysis of S-nitrosylated proteins in Arabidopsis thaliana undergoing hypersensitive response. Proteomics 8, 14591469. doi: $10.1002 /$ pmic. 200700536

Santolini, J., André, F., Jeandroz, S., and Wendehenne, D. (2017). Nitric oxide synthase in plants: where do we stand? Nitric Oxide 63, 30-38. doi: 10.1016/j. niox.2016.09.005

Scheible, W. R., Gonzalez-Fontes, A., Lauerer, M., Muller-Rober, B., Caboche, M., and Stitt, M. (1997). Nitrate acts as a signal to induce organic acid metabolism and repress starch metabolism in tobacco. Plant Cell 9, 783-798. doi: 10.2307/ 3870432

Scheler, C., Durner, J., and Astier, J. (2013). Nitric oxide and reactive oxygen species in plant biotic interactions. Curr. Opin. Plant Biol. 16, 534-539. doi: 10.1016/j.pbi.2013.06.020

Shi, X., Pan, H., Xie, W., Wang, S., Wu, Q., Chen, G., et al. (2017). Different effects of exogenous jasmonic acid on preference and performance of viruliferous Bemisia tabaci B and Q. Entomol. Exp. Appl. 165, 148-158. doi: 10.1111/eea. 12635 
Simontacchi, M., Galatro, A., Ramos-Artuso, F., and Santa-María, G. E. (2015). Plant survival in a changing environment: the role of nitric oxide in plant responses to abiotic stress. Front. Plant Sci. 6:977. doi: 10.3389/fpls.2015.00977

Stam, J. M., Kroes, A., Li, Y., Gols, R., van Loon, J. J., Poelman, E. H., et al. (2014). Plant interactions with multiple insect herbivores: from community to genes. Annu. Rev. Plant Biol. 65, 689-713. doi: 10.1146/annurev-arplant050213-035937

Sun, A., Nie, S., and Xing, D. (2012). Nitric oxide-mediated maintenance of redox homeostasis contributes to NPR1-dependent plant innate immunity triggered by lipopolysaccharides. Plant Physiol. 160, 1081-1096. doi: 10.1104/pp.112. 201798

Tan, X. L., Chen, J. L., Benelli, G., Desneux, N., Yang, X. Q., Liu, T. X., et al. (2017). Pre-infestation of tomato plants by aphids modulates transmission-acquisition relationship among whiteflies, tomato yellow leaf curl virus (TYLCV) and plants. Front. Plant Sci. 8:1597. doi: 10.3389/fpls.2017.01597

Van der Does, D., Leon-Reyes, A., Koornneef, A., Van Verk, M. C., Rodenburg, N., Pauwels, L., et al. (2013). Salicylic acid suppresses jasmonic acid signaling downstream of SCFCOI1-JAZ by targeting GCC promoter motifs via transcription factor ORA59. Plant Cell 25, 744-761. doi: 10.1105/tpc.112. 108548

Van Ree, K. V., Gehl, B., Chehab, E. W., Tsai, Y. C., and Braam, J. (2011). Nitric oxide accumulation in Arabidopsis is independent of NOA1 in the presence of sucrose. Plant J. 68, 225-233. doi: 10.1111/j.1365-313x.2011.04680.x

Wang, C., Xue, M., Bi, M., Li, Q., and Hu, H. (2010). Temporal effect of tobacco defense responses to Myzus perskae (Sulzer)(Homoptera: Aphididae) induced by Bemisia tabaci (Gennadius)(Homoptera: Aleyrodidae) B biotype. Acta Entomol. Sin. 53, 314-322.

Wang, X. W., Li, P., and Liu, S. S. (2017). Whitefly interactions with plants. Curr. Opin. Insect Sci. 19, 70-75. doi: 10.1016/j.cois.2017.02.001

Weech, M. H., Chapleau, M., Pan, L., Ide, C., and Bede, J. C. (2008). Caterpillar saliva interferes with induced Arabidopsis thaliana defence responses via the systemic acquired resistance pathway. J. Exp. Bot. 59, 2437-2448. doi: 10.1093/ jxb/ern 108

Woźniak, A., Formela, M., Bilman, P., Grześkiewicz, K., Bednarski, W., Marczak, $E$, et al. (2017). The dynamics of the defense strategy of pea induced by exogenous nitric oxide in response to aphid infestation. Int. J. Mol. Sci. 18:329. doi: 10.3390/ijms18020329

Wünsche, H., Baldwin, I. T., and Wu, J. (2011a). Silencing NOA1 elevates herbivory-induced jasmonic acid accumulation and compromises most of the carbon-based defense metabolites in Nicotiana attenuata F. J. Integr. Plant Biol. 53, 619-631. doi: 10.1111/j.1744-7909.2011.01040.x

Wünsche, H., Baldwin, I. T., and Wu, J. (2011b). S-Nitrosoglutathione reductase (GSNOR) mediates the biosynthesis of jasmonic acid and ethylene induced by feeding of the insect herbivore Manduca sexta and is important for jasmonateelicited responses in Nicotiana attenuata. J. Exp. Bot. 62, 4605-4616. doi: 10. 1093/jxb/err171

Xu, M. J., Dong, J. F., and Zhu, M. Y. (2005). Nitric oxide mediates the fungal elicitor-induced hypericin production of Hypericum perforatum cell suspension cultures through a jasmonic-acid-dependent signal pathway. Plant Physiol. 139, 991-998. doi: 10.1104/pp.105.066407

Xue, M., Wang, C. X., Bi, M. J., Li, Q. L., and Liu, T. X. (2010). Induced defense by Bemisia tabaci biotype B (Hemiptera: Aleyrodidae) in tobacco against Myzus persicae (Hemiptera: Aphididae). Environ. Entomol. 39, 883-891. doi: 10.1603/ EN09307

Yang, Y. M., Xu, C. N., Wang, B. M., and Jia, J. Z. (2001). Effects of plant growth regulators on secondary wall thickening of cotton fibres. Plant Growth Regul. 35, 233-237. doi: 10.1023/A:1014442015872
Zarate, S. I., Kempema, L. A., and Walling, L. L. (2007). Silverleaf whitefly induces salicylic acid defenses and suppresses effectual jasmonic acid defenses. Plant Physiol. 143, 866-875. doi: 10.1104/pp.106.090035

Zhang, G. F., Lövei, G. L., Hu, M., and Wan, F. H. (2014). Asymmetric consequences of host plant occupation on the competition between the whiteflies Bemisia tabaci cryptic species MEAM1 and Trialeurodes vaporariorum (Hemiptera: Aleyrodidae). Pest Manag. Sci. 70, 1797-1807. doi: $10.1002 /$ ps.3713

Zhang, P. J., Broekgaarden, C., Zheng, S. J., Snoeren, T. A., van Loon, J. J., Gols, R., et al. (2013a). Jasmonate and ethylene signaling mediate whitefly-induced interference with indirect plant defense in Arabidopsis thaliana. New Phytol. 197, 1291-1299. doi: 10.1111/nph.12106

Zhang, S. Z., Huang, H., Shan, H. W., Zhang, F., Wan, F. H., and Liu, T. X. (2013). Defense against $P$ ieris rapae in cabbage plants induced by Bemisia tabaci biotype B. Entomol. Exp. Appl. 147, 293-300. doi: 10.1111/eea.12067

Zhang, P. J., Li, W. D., Huang, F., Zhang, J. M., Xu, F. C., and Lu, Y. B. (2013b). Feeding by whiteflies suppresses downstream jasmonic acid signaling by eliciting salicylic acid signaling. J. Chem. Ecol. 39, 612-619. doi: 10.1007/ s10886-013-0283-2

Zhang, P. J., He, Y. C., Zhao, C., Ye, Z. H., and Yu, X. P. (2018). Jasmonic acid-dependent defenses play a key role in defending tomato against Bemisia tabaci nymphs, but not adults. Front. Plant Sci. 9:1065. doi: 10.3389/fpls.2018. 01065

Zhang, P. J., Huang, F., Zhang, J. M., Wei, J. N., and Lu, Y. B. (2015). The mealybug Phenacoccus solenopsis suppresses plant defense responses by manipulating JA-SA crosstalk. Sci. Rep. U. K. 5:9354. doi: 10.1038/srep0 9354

Zhang, P. J., Zheng, S. J., van Loon, J. J., Boland, W., David, A., Mumm, R., et al. (2009). Whiteflies interfere with indirect plant defense against spider mites in Lima bean. Proc. Natl. Acad. Sci. U.S.A. 106, 21202-21207. doi: 10.1073/pnas. 0907890106

Zhang, X., Sun, X., Zhao, H., Xue, M., and Wang, D. (2017). Phenolic compounds induced by Bemisia tabaci and Trialeurodes vaporariorum in Nicotiana tabacum L. and their relationship with the salicylic acid signaling pathway. Arthropod Plant Interact. 11, 659-667. doi: 10.1007/s11829-017-9508-6

Zhang, X., Xue, M., and Zhao, H. (2015). Species-specific effects on salicylic acid content and subsequent Myzus persicae (Sulzer) performance by three phloemsucking insects infesting Nicotiana tabacum L. ArthropodPlant Interact. 9, 383-391. doi: 10.1007/s11829-015-9385-9

Zhao, P. Z., Yao, X. M., Cai, C. X., Li, R., Du, J., Sun, Y. W., et al. (2019). Viruses mobilize plant immunity to deter nonvector insect herbivores. Sci. $A d v$. 5:eaav9801. doi: 10.1126/sciadv.aav9801

Zhou, J., Jia, F., Shao, S., Zhang, H., Li, G., and Xia, X. (2015). Involvement of nitric oxide in the jasmonate-dependent basal defense against root-knot nematode in tomato plants. Front. Plant Sci. 6:193. doi: 10.3389/fpls.2015. 00193

Conflict of Interest: The authors declare that the research was conducted in the absence of any commercial or financial relationships that could be construed as a potential conflict of interest.

Copyright (C) $2020 \mathrm{Xu}, \mathrm{Qu}, \mathrm{Sun}, \mathrm{Jia}, \mathrm{Xue}, \mathrm{Zhao}$ and Zhou. This is an open-access article distributed under the terms of the Creative Commons Attribution License (CC BY). The use, distribution or reproduction in other forums is permitted, provided the original author(s) and the copyright owner(s) are credited and that the original publication in this journal is cited, in accordance with accepted academic practice. No use, distribution or reproduction is permitted which does not comply with these terms. 